\title{
Nuclear factor $\kappa \mathrm{B}$ in liver disease
}

Li Q, Van Antwerp D, Mercurio F, et al. Severe liver degeneration in mice lacking the I $\mathrm{KB}$ kinase 2 gene. Science 1999;284:321-5.

\begin{abstract}
Phosphorylation of inhibitor of $\kappa B$ (IкB) proteins is an important step in the activation of the transcription nuclear factor $\kappa B(N F-\kappa B)$ and requires two IKB kinases, IKK1 (IKK $\alpha$ ) and IKK2 (IKK $\beta)$. Mice that are devoid of the IKK2 gene had extensive liver damage from apoptosis and died as embryos, but these mice could be rescued by the inactivation of the gene encoding tumor necrosis factor receptor 1. Mouse embryonic fibroblast cells that were isolated from IKK2-Iembryos showed a marked reduction in tumor necrosis factor- $\alpha$ (TNF- $\alpha$ )- and interleukin-1 $\alpha$ induced NF- $\kappa \mathrm{B}$ activity and an enhanced apoptosis in response to TNF- $\alpha$. IKK1 associated with NF- $\kappa B$ essential modulator (IKK $\gamma / I K K A P 1)$, another component of the IKK complex. These results show that IKK2 is essential for mouse development and cannot be substituted with IKK1.
\end{abstract}

\section{Comment}

The control of gene expression by transcription factors is central to the development and regulated function of multicellular organisms. Perhaps the best understood group of transcription factors is the nuclear factor (NF) $\kappa \mathrm{B}$ family, the members of which, in response to activation by a range of extracellular factors, regulate the expression of genes responsible for promoting inflammation and modulating apoptotic responses. Interested readers may wish to refer to a recent review on this topic by Neurath et al. ${ }^{1} \mathrm{NF}-\kappa \mathrm{B}$ is composed of homodimers and heterodimers of members of the Rel protein family, the most ubiquitous being p65/RelA which typically heterodimerises with p50 to form active transcription factor complexes. It is not surprising that $\mathrm{NF}-\kappa \mathrm{B}$ activation is tightly regulated via a cascade of kinase reactions mediated by a multiprotein complex. The key event after stimulation (usually by the binding of cytokines such as tumour necrosis factor (TNF) $\alpha$ and interleukin (IL) 1 to their cell surface receptors) is the phosphorylation and subsequent degradation of inhibitors (I) of $\kappa \mathrm{B}$ proteins $(\mathrm{I} \kappa \mathrm{B} \alpha$ and $\mathrm{I} \kappa \mathrm{B} \beta$ ). This results in the release of previously bound $\mathrm{NF}-\kappa \mathrm{B}$ so that it can translocate to the nucleus where it transactivates genes by binding to specific sequences in their promoters. Two I $\mathrm{B}$ kinases, IKK 1 and IKK2 (also known as IKK $\alpha$ and IKK $\beta$ ) are responsible for phosphorylating $I \kappa B$ and these share significant sequence and structural homology. The IKK complex contains the catalytic subunits IKK1 and IKK2 heterotrimerised with the regulatory subunit IKK $\gamma$ (also known as NEMO). ${ }^{23}$

The relative role of the IKKs in $\mathrm{NF}-\kappa \mathrm{B}$ activation via different signals and their subsequent contribution to vari- ous downstream effects is now revealed by a number of recently published papers which provide some unpredictable but fascinating insights. Li et al found that mice lacking the IKK2 gene (IKK2-/-) died between embryonic day 12.5 and 14 from massive hepatocyte apoptosis. The morphology of these embryos was otherwise normal. The presence of nucleated and enucleated erythrocytes in the apoptotic livers implied that haematopoiesis was proceeding normally. Reduced $\mathrm{NF}-\kappa \mathrm{B}$ binding activity in response to TNF- $\alpha$ or IL- $1 \alpha$ stimulation in embryonic fibroblasts isolated from the IKK2-/- animals was also shown and, consistent with the anti-apoptotic role of $\mathrm{NF}-\kappa \mathrm{B}$, the IKK2-/- fibroblasts were more sensitive to TNF- $\alpha$ induced apoptosis. To investigate whether or not hepatocyte apoptosis in the IKK2-/- embryos was mediated via TNF receptor 1 (TNFR1), IKK $2+/-$ mice were crossed with TNFR1-/- mice. This cross produced viable "double knockout" progeny (IKK2-/-, TNFR1-/-) demonstrating that inactivation of the TNFR1 gene rescues the embryonic lethality of IKK2 deficiency. This suggests that the IKK2-/- mice die from TNF- $\alpha$ induced hepatocyte apoptosis. Interestingly p65/RelA knock out mice have a similar phenotype to IKK-/- mice with embryonic lethality due to liver degeneration with hepatocyte apoptosis. ${ }^{4}$ Thus, IKK2 is essential for the activation of p65/RelA in hepatocytes and this effect is important for normal liver development. These observations have been verified independently by a similar study from Tanaka et $a l .^{5}$

Where do these studies leave our understanding of the control of the NF- $\mathrm{BB}$ pathway? The reports that accompany Li et al describe an intriguing role for IKK1 in multiple morphogenic events including limb development, skeletal patterning and epidermal differentiation. ${ }^{67}$ These findings are perhaps not surprising given the central role of dorsal, the NF- $\mathrm{\kappa B}$ homologue in Drosophila, in embryonic patterning and the regulation of genes important for early development. ${ }^{8}$ What is surprising is that IKK1 and IKK2 seem to mediate $\mathrm{NF}-\kappa \mathrm{B}$ activation via different signals (IKK1 responds to morphogenic signals whereas IKK2 mediates cytokine responses) which result in distinct effects on early development. Further evidence for this model was provided by the observation that mutation of the activation loop of IKK 2 abrogated TNF- $\alpha$ and IL-1 induced IKK activation whereas disruption of the equivalent region in IKK1 had no effect. ${ }^{9}$ These differences will influence signalling in adult tissues and the challenge is now to define the relative role of the IKKs in inflammatory versus apoptotic responses and to determine how the IKK complex can transmit different signals which result in distinct effects. Clearly this work raises the possibility that specific targeting of the $\mathrm{IKK} 2 / \mathrm{I} \kappa \mathrm{B} / \mathrm{NF}-\kappa \mathrm{B}$ pathway may have major therapeutic potential in malignant and inflammatory conditions of the liver.

N J GALLAGHER L S YOUNG

Institute for Cancer Studies, University of Birmingham Medical School, Edgbaston, 
Birmingham B15 2TA, UK Email: n.j.gallagher@bham.ac.uk

1 Neurath MF, Becker C, Barbulescu K. Role of NF- $\mathrm{kB}$ in immune and inflammatory responses in the gut. Gut 1998;43:856-60.

2 Rothwarf DM, Zandi E, Natoli G, et al. IKK $\gamma$ is an essential regulatory subunit of the IкB kinase complex. Nature 1998;395:297-300.

3 Yamaoka S, Courtois G, Bessia C, et al. Complementation cloning of

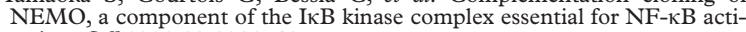
vation. Cell 1998;93:1231-40

4 Beg AA, Sha WC, Bronson RT, et al. Emryonic lethality and liver degeneration in mice lacking the RelA component of NF-кB. Nature 1995;376:16770 .
5 Tanaka M, Fuentes ME, Yamaguchi $\mathrm{K}$, et al. Embryonic lethality, liver degeneration, and impaired NF-KB activation in IKK $\beta$-deficient mice. Immunity 1999;10:421-9.

6 Takeda K, Takeuchi O, Tsujimura T, et al. Limb and skin abnormalities in mice lacking IKK $\alpha$. Science 1999;284:313-16.

$7 \mathrm{Hu}$ Y, Baud V, Delhase M, et al. Abnormal morphogenesis but intact IKK activation in mice lacking the IKK $\alpha$ subunit of IאB kinase. Science 1999;284:316-20.

8 St Johnston D, Nusslein-Vollard C. The origin of pattern and polarity in the drosophila embryo. Cell 1992;68:201-19.

9 Delhase $M$, Hayakawa M, Yi C, et al. Positive and negative regulation of IкB kinase activity through IKK $\beta$ subunit phosphorylation. Science 1999;284: 309-13. 